\title{
Music in the operating theatre: to listen or not to listen remains a question?
}

\author{
Dr Yam Bahadur Roka \\ MS, M.Ch., IFAANS \\ Senior Consultant and Head \\ Department of Neurosurgery \\ Neuro Cardio and MultiSpeciality hospital, Biratnagar, \\ Nepal \\ dryamroka@yahoo.com
}

\begin{abstract}
"If I had my life to live over again, I would have made a rule to read some poetry and listen to some music at least once every week.” Charles Darwin
\end{abstract}

Everyone loves music and I am sure there are few who dislike it. The universal sound of the universe is the "Om" which has been used as spiritual science and for enlightenment.

The beneficial effects of music have been well studied in science and some of the advantages are raising IQ, reduce stress and anxiety, decreases pain, increases happiness, helps improve memory and reduce Alzheimer's and makes sleep better. ${ }^{5}$ The first instance of music playing in the operating theatre (OT) was in 1914, when Evan O’Neill Kane used as an anxiety-relieving measure for patients undergoing anaesthesia. ${ }^{10}$

There are many studies of the effect of music in the OT. In the UK it was found in a study that $90 \%$ of the surgeons played music during surgery. ${ }^{2}$ Another study it was found that music helped to heal wound better, reduced the time for surgery in the OT and thereby reducing the overall cost of the procedure. ${ }^{6}$ Any music can be played in the OT from Jazz, Heavy Metal, Drums, Fusion, Rock, Rap to Classical. Classical music, English melodies, Country songs, FM radio, Hindi classics or Ghazals with its absence of lyrics/soft soundwas chosen most often in OT due to its alert inducing properties. ${ }^{3}$ Classically the surgeon has been described as (Myers-Briggs Type Indicator (MBTI)) has favored the ESTJ personality type [extroversion(E), sensing (S), thinking $(\mathrm{T})$, and judging $(\mathrm{J})]$. It was also found that the intuitive types of personality, which the surgeon is a kind,favored music during surgery. ${ }^{8}$ The best music tempo for relaxation has been found at the rate of $60-80$ beats per minute and medium range volume is preferable over high or low volume.

But is it all "only good" with music and should it be played universally in all OT worldwide? Although there are strong proponents of the good effects of music there are many who disagree. In many studies it has been found that music hampers the ability to make fast decision, increases surgery time, leads to distraction, hampers in communication, is not fear allying to the patient, increases infection and increases irritation. ${ }^{1,4}$ Loud music can hamper in detection of the emergency monitor sounds, can lead to wastage of time in song selection, repeated request for an instrument and even dispute over particular song type. ${ }^{3}$ Music was also found to be annoying by many anesthesiologist and nurses in few studies. ${ }^{1,10}$ World Health organization has limited the volume in OT to $30 \mathrm{~dB}$, but many theatres exceed this limit to $65 \mathrm{~dB}$ and even up to $70 \mathrm{~d}$ Bwhen music is playing, thus to the extent of noise pollution. Music can thus add to the noise and lead to miscommunication. ${ }^{10}$ Since the music is largely dependent on the surgeons preference, the other staff members especially the nurses may not agree to the formers choice thus feeling that it's been forced upon them, leading to distraction. ${ }^{10}$ 
Many surgeons and OT staff believe that music helps to perform better while others may feel that it hampers their concentration especially during difficult situation especially with high volume. ${ }^{2,7,9}$ It has also been found that music can help to alleviate preoperative stress in both the patient and the surgeon. It also acts as a mind relaxant and in some cases better than preoperative midazolam with the effects lasting to postoperative period.It also has its own side effects and hence it must be individualized after a formal discussion amongst all OT personnel regarding its use in the OT. Institute rules, ethical concerns, preference by the neurosurgeon or other theatre staff and the socio-geographic background may limit the use of music in the OT.

\section{References:}

1. Ahmad M. Role of Music in Operating Room. J Anesth Crit Care Open Access 7 (5): 00279, 2017

2. Allen K, Blascovic J. Effects of music on cardiovascular reactivity among surgeons. JAMA 272 (11): 882-884, 1994
3. George S, Ahmed S, Mammen KJ, John GM. Influence of music on operation theatre staff. J Anaesthesiol Clin Pharmacol 27 (3):354-357, 2011

4. Hawksworth C, Asbury AJ, Millar K. Music in theatre: not so harmonious. A survey of attitudes to music played in the operating theatre. Anaesthesia 52:79-83, 1997

5. https://www.healthfitnessrevolution.com/top-10benefits-listening-music/ (Accessed in May 2019)

6. Lies, SR, Zhang, AY. Prospective Randomized Study of the Effect of Music on the Efficiency of Surgical Closures. Aesthetic Surgery Journal 35 (7) :858863, 2015

7. Peretti PO, Swenson E. Effects of music on anxiety as determined by physiological skin responses. J Res Music Educ 22 (4): 278-281, 1974

8. Swanson, JA, Antonoff, MB, D’Cunha, J, Maddaus, MA. Personality Profiling of the Modern Surgical Trainee: Insights into Generation X. Journal of Surgical Education 67 (6:, 417-420, 2010

9. Ullmann Y, Foder L, Schwarzberg I, Carmi N, Ullmann A, et al. The sounds of music in the operating room. Injury 39 (5): 592-597, 2006

10. Weldon, S-M, Korkiakangas, T, Bezemer, J, Kneebone, R. (2015). Music and communication in the operating theatre. Journal of Advanced Nursing 71 (12): 2763-2774, 2015 